University of Nebraska - Lincoln

DigitalCommons@University of Nebraska - Lincoln

USDA National Wildlife Research Center - Staff Publications
U.S. Department of Agriculture: Animal and Plant Health Inspection Service

January 2003

\title{
A general model for predicting brown tree snake capture rates
}

Richard M. Engeman

USDA-APHIS-Wildlife Services, s_r100@yahoo.com

N. Paige Groninger

USDA-APHIS-Wildlife Services

Daniel S. Vice

USDA-APHIS-Wildlife Services

Follow this and additional works at: https://digitalcommons.unl.edu/icwdm_usdanwrc

Part of the Environmental Sciences Commons

Engeman, Richard M.; Groninger, N. Paige; and Vice, Daniel S., "A general model for predicting brown tree snake capture rates" (2003). USDA National Wildlife Research Center - Staff Publications. 175.

https://digitalcommons.unl.edu/icwdm_usdanwrc/175

This Article is brought to you for free and open access by the U.S. Department of Agriculture: Animal and Plant Health Inspection Service at DigitalCommons@University of Nebraska - Lincoln. It has been accepted for inclusion in USDA National Wildlife Research Center - Staff Publications by an authorized administrator of DigitalCommons@University of Nebraska - Lincoln. 


\title{
A general model for predicting brown tree snake capture rates
}

\author{
Richard M. Engeman ${ }^{1, *, \dagger}$, N. Paige Groninger ${ }^{1}$ and Daniel S. Vice ${ }^{2}$ \\ ${ }^{1}$ National Wildlife Research Center, 4101 LaPorte Ave, Fort Collins, CO 80521-2154, U.S.A \\ ${ }^{2}$ USDA/APHIS/WS, 1060 Route 16, Suite 103-C, Barrigada Heights, GU 96921, U.S.A
}

\begin{abstract}
SUMMARY
The inadvertent introduction of the brown tree snake (Boiga irregularis) to Guam has resulted in the extirpation of most of the island's native terrestrial vertebrates, has presented a health hazard to small children, and also has produced economic problems. Trapping around ports and other cargo staging areas is central to a program designed to deter dispersal of the species. Sequential trapping of smaller plots is also being used to clear larger areas of snakes in preparation for endangered species reintroductions. Traps and trapping personnel are limited resources, which places a premium on the ability to plan the deployment of trapping efforts. In a series of previous trapping studies, data on brown tree snake removal from forested plots was found to be well modeled by exponential decay functions. For the present article, we considered a variety of model forms and estimation procedures, and used capture data from individual plots as random subjects to produce a general random coefficients model for making predictions of brown tree snake capture rates. The best model was an exponential decay with positive asymptote produced using nonlinear mixed model estimation where variability among plots was introduced through the scale and asymptote parameters. Practical predictive abilities were used in model evaluation so that a manager could project capture rates in a plot after a period of time, or project the amount of time required for trapping to reduce capture rates to a desired level. The model should provide managers with a tool for optimizing the allocation of limited trapping resources. Copyright (C) 2003 John Wiley \& Sons, Ltd.
\end{abstract}

KEY WORDS: exotic species; invasive species; nonlinear mixed model; random coefficient growth curves

\section{INTRODUCTION}

The brown tree snake (Boiga irregularis) on Guam is a severe example of the effects that an introduced predator can have on insular populations of native fauna. After the accidental introduction of the brown tree snake to Guam in the 1940s, this species has extirpated nearly all of the native forest avifauna (Savidge, 1987). The fruit bat populations on Guam, already severely impacted by hunting, have suffered additionally through brown tree snake predation (Wiles, 1987). Several indigenous or endemic species of lizards also have been extirpated or endangered (Rodda and Fritts, 1992). The brown tree snake on Guam also has become an agricultural (Fritts and McCoid, 1991) and economic pest (Fritts et al., 1987). Furthermore, this rear-fanged colubrid snake is mildly venomous and poses a potential health hazard to infants and young children (Fritts et al., 1990).

*Correspondence to: Richard M. Engeman, National Wildlife Research Center, 4101 LaPorte Ave, Fort Collins, CO 80521-2154, U.S.A.

†E-mail: richard.m.engeman@usda.gov

Published online 24 January 2003

Copyright (C) 2003 John Wiley \& Sons, Ltd.

Received 20 November 2001

Revised 25 August 2002 
The brown tree snake may impact other islands in the future, as it is well adapted for successful transport to other locations. They are agile climbers that seek refuge from heat and light during daytime, and cargo, shipping containers, and transport vessels can offer ready daytime refugia. The snakes are opportunistic feeders that consume a highly varied diet and can survive an extended period without food (Greene, 1989; Linnell et al., 1997; Rodda et al., 1999; Savidge, 1988; Shine, 1991; Shivik and Clark, 1999). Furthermore, mitochondrial DNA evidence suggests that very few female brown tree snakes (possibly only one) originated the Guam population (Rawlings et al., 1998). These elements, coupled with the high snake densities and Guam's position as a focal point for commercial and military shipments of cargo and passengers throughout the western Pacific, magnify the likelihood for further dispersal of brown tree snakes from Guam. Brown tree snake sightings have already been documented on many Pacific islands (Fritts et al., 1999), with an incipient population speculated to exist on Saipan in the Commonwealth of the Northern Mariana Islands (McCoid et al., 1994).

Trapping is an essential component in integrated control programs on Guam to remove brown tree snakes from plots of land. Removal is conducted in port and cargo staging areas to produce lowpopulation buffer zones as a means of deterring brown tree snake entry to outbound cargo. Sequential trapping of smaller plots of forested habitat is being used in conjunction with snake barrier technology to reclaim larger areas for protection and reintroduction of endangered species.

Brown tree snake traps follow a basic crayfish or minnow trap design, customized for brown tree snake capture (e.g. Linnell et al., 1998). A live mouse, protected in an interior cage, is used as an attractant to lure the snakes through one-way doors into the traps. Traps in control programs are checked weekly for snake captures, because this is the frequency with which the mice used as attractants require maintenance in the field (food, water source, chamber cleaning).

Trapping has been demonstrated to be highly effective at catching brown tree snakes in a number of studies (e.g. Engeman et al., 1998a; Engeman and Linnell, 1998). However, trapping brown tree snakes is a labor-intensive procedure, primarily due to the effort required to maintain the mice in healthy condition. Managers responsible for controlling brown tree snakes often find traps to be a limited resource, restricting the extent to which snake removal can be applied. Compunding the problem, Guam's climate and weather can rapidly deteriorate trap components, and nontarget captures such as coconut crabs (Birgus latro) and rats (Rattus spp.) cause considerable damage to traps. Also, feral dogs (Canis familiaris) and feral pigs (Sus scrofa) often destroy traps in an effort to get at the food for the mice, and traps also are frequently vandalized or removed by people.

Traps typically are placed on the perimeter of a plot targeted for snake removal, as this is an effective and labor-efficient trap placement strategy (Engeman and Linnell, 1998; Engeman et al., 1998b). Trap spacing averages about $20 \mathrm{~m}$, so a manager can easily gauge the number of traps needed for a particular plot. There are far more sites in need of brown tree snake trapping on Guam than there are traps, personnel and support materials needed to simultaneously carry out the effort. Thus, some or all traps are often removed from a plot after snake captures have become and remain much reduced for a period of time. Moving traps allows control efforts to be applied to a wider area. The weekly capture rates for removing brown tree snakes from individual plots in several trapping studies have been well described by exponential decay functions (Engeman and Linnell, 1998; Engeman and Linnell, in press; Engeman et al., 2000). If managers could gauge the time required to reduce a snake population to a certain level, then trapping resources and work schedules could be more efficiently planned, especially when a coordinated effort is made to remove brown tree snakes from a larger area comprised of smaller plots. Here we use the information from multiple plots to create an overall model for describing the removal rate of brown tree snakes from a generic forested plot on Guam. 
Table 1. Description of the data sources for the plots used in this study to produce random coefficient decay models for describing brown tree snake removal by trapping

\begin{tabular}{lccl}
\hline $\begin{array}{l}\text { Plot } \\
\text { number }\end{array}$ & Size (ha) & $\begin{array}{c}\text { When } \\
\text { trapped }\end{array}$ & Citation \\
\hline 1 & 6.1 & 1995 & Engeman and Linnell (1998) \\
2 & 6.1 & 1995 & $"$ \\
3 & 6.1 & 1995 & $"$ \\
4 & 3.6 & 1995 & Engeman et al. (2000) \\
5 & 17.8 & 1997 & Engeman and Linnell (in press) \\
6 & 6.1 & 1996 & $"$ \\
7 & 5.3 & 1996 & $"$ \\
8 & 6.1 & 1996 & \\
\hline
\end{tabular}

\section{METHODS}

Rigorously collected data on brown tree snake removal by trapping with standard operational procedures were available from eight plots of land. The perimeters of each plot were well defined by roads, tracks, or other man-made disruptions to the forest. Some of the characteristics of the plots and trapping history are given in Table 1, along with citations for obtaining more detailed descriptions of the plots. Data were collected on a weekly basis because snakes were removed from the traps once per week when the live mice used as attractants were maintained. The capture rate data from each plot had previously produced plot-specific simple exponential decay models of the form

$$
y_{j}=a \mathrm{e}^{-b x_{j}}
$$

where $y_{j}$ represents the capture rate as brown tree snakes per trap-night (bts/tn) for the $j$ th week, $x_{j}$ is the $j$ th week, $a$ is a scale parameter and $b$ is a rate parameter. We considered two approaches for developing a general random coefficient model of this form for describing brown tree snake removals by trapping.

\subsection{Linear mixed model}

The data were fitted by first linearizing the equation with a $\log$ transform and conducting a linear regression on

$$
z_{j}=k-b x_{j}
$$

where $z_{j}=\ln \left(y_{j}\right)$ and $k=\ln (a)$ is the intercept.

Next, the log-transformed data from all plots were analyzed together in a mixed linear model structure with random coefficients representing a random selection of potential exponential decay models for describing brown tree snake removal from such plots on Guam (e.g. Littell et al., 1996; Grizzle and Allen, 1969; Laird and Ware, 1982; Rao, 1965):

$$
z_{i j}=k_{i}-b_{i} x_{i j}+e_{i j}
$$


where $z_{i j}$ is the natural $\log$ of the capture rate for the $j$ th week on the $i$ th plot. The general descriptive model for brown tree snake removal by trapping was the resulting average population model (Zeger et al., 1988). Calculations were carried out using SAS PROC MIXED (Littell et al., 1996; SAS Institute, 1999), where $k$ and $b$ in the above equation were included in the RANDOM statement while specifying the SUBJECT $=$ PLOT option to instruct the program on changing individual models as plots changed. Back-transforming the general regression model produced a general simple exponential decay model.

\subsection{Nonlinear mixed model}

A generalization to the random coefficients model fitted as a linear mixed model is to allow the coefficients to enter the model nonlinearly (e.g. Wolfinger, 1999). We consider a nonlinear random coefficients model of the form

$$
y_{i j}=a \mathrm{e}^{-b x_{j}}+e_{i j}
$$

where $y_{i j}$ represents the capture rate of brown tree snakes per trap-night for the $j$ th week on the $i$ th plot, and $a$ and $b$ are, respectively, the scale and rate parameters, potentially varying among plots. Two approaches for fitting this model were considered. The simpler of the two was to assume that the random effect among plots enters the model through only one parameter, either as $a+u$ or $b+u$, where $u \sim \mathrm{N}\left(0, \sigma_{u}^{2}\right)$. The more complex approach was to allow both parameters to vary among plots, where $a$ and $b$ enter the model as $a+u$ and $b+v$, with $u \sim \mathrm{N}\left(0, \sigma_{u}^{2}\right)$ and $v \sim \mathrm{N}\left(0, \sigma_{v}^{2}\right)$. For each case, calculations were carried out using SAS PROC NLMIXED (SAS Institute, 1999; Wolfinger, 1999), where the equation (including $u$ and $v$ ) was included in the RANDOM statement while specifying the SUBJECT $=$ PLOT option to instruct the program on changing individual models as plots changed. All parameters were restricted to be $\geq 0$.

\subsection{Other nonlinear mixed models}

We also considered the possibility that other model forms might better describe the decay in capture rates over time than the simple exponential decay. First, we examined the possibility of a nonzero (positive) asymptote using the model

$$
y_{i j}=c+a \mathrm{e}^{-b x_{i j}}+e_{i j}
$$

where an asymptote, $c$, is added to the exponential decay. A general model of this form was also fitted using PROC NLMIXED, with $c$ bounded as $c>0$.

We also considered whether a mixed-order model (Stowe et al., 1999) would better describe the decaying capture rates over time:

$$
y_{i j}=\left\{a^{(1-d)}-b x_{i}(1-d)\right\}^{1 /(1-d)}+e_{i j}
$$

where $d$ is a pseudo-order parameter (Stowe et al., 1999). When $d=1$, the above mixed order model is defined as the simple exponential decay. Larger values of $d$ produce more rapid initial decreases, followed by progressively slower rates of decrease over time (Stowe et al., 1999). A general random coefficient model of this form was also fitted to the data from all plots using PROC NLMIXED, with $d$ bounded as $d>1$. 


\subsection{Model practicality}

Prior to carrying out estimation of a general model, we defined two ways in which a model's practicality could be examined. First, predictions on the capture rates of brown tree snakes after a specified period of trapping were to be made and compared to the actual observations from each plot. The second criteria was to use the general model in a calibration approach (e.g. Graybill, 1976) to predict, based on the first week's capture rate, the additional number of weeks of trapping needed to decrease to a target capture rate.

For the first case we selected prediction of the capture rate at four weeks as a criterion. From a theoretical standpoint, the optimal points for assessing an exponential decay curve are at the initial time and the time at which 63 per cent of the decay has occurred (Box and Lucas, 1959; Eberhardt and Thomas, 1991), and the 4-week time frame allowed each of the individual plots to achieve this level of decay. Also from an applied standpoint, 4 weeks represented a practical time unit for managers to easily apply to field logistics, and all plots had been observed for over one month. For the second criteria we chose a target capture rate of $0.03 \mathrm{bts} / \mathrm{tn}$. From predator-prey theory, the $0.03 \mathrm{bts} / \mathrm{tn}$ capture rate would be beyond the optimal time for all plots where a foraging predator should stop seeking prey in that plot and move elsewhere to forage (Begon et al., 1996), i.e. it is a conservative time point whereby traps should be moved to another plot. Also from our field experience, this low capture rate is where trapping produces diminishing returns relative to effort, and a manager seeking to maximize results would usually consider moving traps to another area.

Because we only had eight plots from which capture data was rigorously collected, with no immediate prospects for obtaining additional reliable data from new plots for validation, we crossvalidated results from promising models by applying the above methods while excluding the data from one plot at a time and using the excluded plot for evaluating the resultant model.

\section{RESULTS}

An overview of the model fitting approaches for producing general random coefficients models is presented in Table 2. Selection of the model most useful for practical application for the snake control program on Guam invites several angles of examination among these models.

Table 2. Overview of model forms, estimation procedures and parameter estimates for producing a general random coefficients decay curve for describing the removal of brown tree snakes by trapping forested plots of land on Guam

\begin{tabular}{llrr}
\hline Model form & Estimation procedure for general model & Parameter estimates & AICC \\
\hline$y=a \mathrm{e}^{-b x}$ & Log-transform of $y$, linear mixed model & $=0.208,=0.578$ & $*$ \\
& Nonlinear mixed model, $a$ varied by plot & $=0.365,=0.815$ & -178.4 \\
& Nonlinear mixed model, $b$ varied by plot & $=0.410,=1.022$ & -170.0 \\
& Nonlinear mixed model, $a$ \& $b$ varied by plot & $=0.369,=0.828$ & -176.3 \\
$y=c+a \mathrm{e}^{-b x}$ & Nonlinear mixed model, $a$ varied by plot & $=0.465,=1.162,=0.018$ & -187.3 \\
& Nonlinear mixed model, $a$ \& $c$ varied by plot & $=0.510,=1.261,=0.020$ & -189.3 \\
& Nonlinear mixed model, $d$ varied by plot & $=2.041,=4.326,=1.380$ & -175.3 \\
& Nonlinear mixed model, $a$ varied by plot & $=0.828,=2.945,=1.380$ & -184.5
\end{tabular}

*The AICC for this model derives from transformed data and is not comparable to the others.

$$
y=\left\{a^{(1-d)}-b x(1-d)\right\}^{1 /(1-d)}
$$


We first consider the simple exponential decay model results (Table 2). Without undue surprise, the general model produced by first log-transforming the capture rates and applying mixed linear model procedures resulted in a parameterization different from that for the nonlinear mixed model results. For nonlinear mixed model estimation, allowing the between plot variability to be added to the rate parameter (b) in addition to the scale parameter (a) did not improve estimation, and the parameter estimates remained virtually the same. Having plot variability enter through the rate parameter only produced a substantially different parameterization and inferior estimation.

Addition of a nonzero asymptote to the simple exponential for nonlinear mixed model estimation improved results (Table 2). The best model allowed plot variability to be added to the scale parameter and to the asymptote parameter. Lastly, we estimated the parameters of the mixed order-model form in Equation (6) using nonlinear mixed model estimation. Plot variability was introduced through the scale parameter (a) or through the pseudo-order parameter (d). Neither model was an improvement over the exponential decay with a positive asymptote (Table 3). Reliable estimates could not be produced when plot variability was introduced through more than one parameter.

We examined model practicality for the simple exponential decay model produced through log transformation and mixed linear model estimation and for the best model produced through nonlinear mixed model estimation (the exponential decay with positive asymptote where plot variability entered the model through both the scale and asymptote parameters). Out of natural interest, we also considered the best simple exponential decay model produced through nonlinear mixed model estimation (variability entered through the scale parameter). These three models are graphically superimposed over the capture rate results from each of the eight plots in Figure 1. The results from examining the model practicality criteria in Table 3 showed similar prediction for the exponential decay with asymptote and the simple exponential decay model produced by log-transformation with mixed linear model estimation. Both models predicted the capture rate at four weeks of trapping to be $0.02 \mathrm{bts} / \mathrm{tn}$, which served well as a prediction for most plots (Table 3). Only two of the eight plots had capture rates that exceeded the predicted value of $0.02 \mathrm{bts} / \mathrm{tn}$. Five of the eight plots actually had capture rates of $0.02 \mathrm{bts} / \mathrm{tn}$. The best simple exponential decay model produced through nonlinear

Table 3. Predictions from three potential models (first, second and fifth models in Table 2) of the brown tree snake weekly capture rate over time from eight individual plots on Guam

\begin{tabular}{|c|c|c|c|c|c|c|c|c|}
\hline \multirow[b]{4}{*}{ Plot } & \multicolumn{4}{|c|}{ Capture rate at 4 weeks } & \multicolumn{4}{|c|}{$\begin{array}{l}\text { Additional weeks }{ }^{\mathrm{a}} \text { until capture } \\
\text { rate of } 0.03 \mathrm{bts} / \mathrm{tn}\end{array}$} \\
\hline & & & & Nonlinear + & & & & Nonlinear + \\
\hline & & Linear & Nonlinear & Asymptote & & Linear & Nonlinear & Asymptote \\
\hline & Observed & Predicted & Predicted & Predicted & Observed & Predicted & Predicted & Predicted \\
\hline 1 & 0.02 & 0.02 & 0.01 & 0.02 & 3 & 3 & 2 & 2 \\
\hline 2 & 0.02 & 0.02 & 0.01 & 0.02 & 2 & 4 & 3 & 3 \\
\hline 3 & 0.05 & 0.02 & 0.01 & 0.02 & 4 & 3 & 2 & 2 \\
\hline 4 & 0.02 & 0.02 & 0.01 & 0.02 & 1 & 3 & 2 & 2 \\
\hline 5 & 0.02 & 0.02 & 0.01 & 0.02 & 1 & 1 & 1 & 1 \\
\hline 6 & 0.02 & 0.02 & 0.01 & 0.02 & 2 & 2 & 2 & 2 \\
\hline 7 & 0.04 & 0.02 & 0.01 & 0.02 & $>4^{\mathrm{b}}$ & 3 & 2 & 2 \\
\hline 8 & 0.01 & 0.02 & 0.01 & 0.02 & 1 & 3 & 2 & 2 \\
\hline
\end{tabular}

${ }^{\mathrm{a}}$ Presented in whole numbers as traps are checked on a weekly basis.

${ }^{\mathrm{b}}$ Minimum observed capture rate during 5 weeks of trapping was $0.037 \mathrm{bts} / \mathrm{tn}$. 


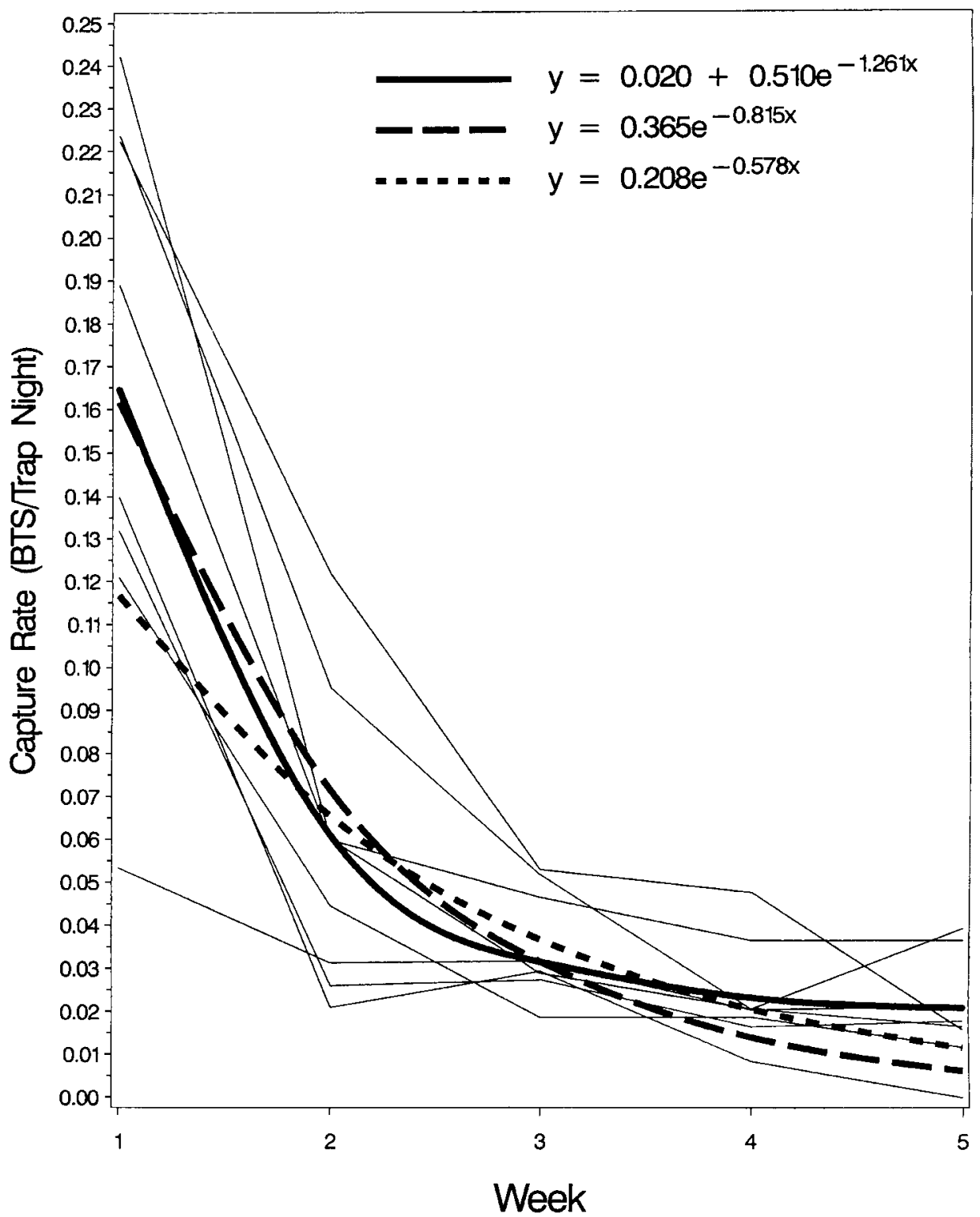

Figure 1. Graphs in bold face are brown tree snake capture rates over time for the simple exponential decay curve fitted by logtransformation of the capture rate and mixed linear model estimation, the simple exponential decay fitted using nonlinear mixed model estimation, and the exponential decay with positive asymptote fitted using nonlinear mixed model estimation. The model graphs are superimposed over the observed capture rates from eight forested plots on Guam 
mixed model estimation predicted a capture rate of $0.01 \mathrm{bts} / \mathrm{tn}$, which underestimated the observed capture rate at four weeks for seven of the eight plots.

As would be expected when conducting calibration predictions as the curve begins to asymptote, more variability was displayed when estimating the additional amount of time beyond one week of trapping to achieve a target capture rate of $0.03 \mathrm{bts} / \mathrm{tn}$ (Table 3). The observed capture rate on one plot decreased to $0.037 \mathrm{bts} / \mathrm{tn}$ in three weeks, but subsequently remained at this level without going below our test target of $0.03 \mathrm{bts} / \mathrm{tn}$, meaning none of the models could accurately predict that plot's results. Thus, the remaining seven plots provided the basis for this evaluation criteria. The exponential decay with positive asymptote and the simple exponential decay model produced through nonlinear mixed model estimation each showed a 0 average bias over the seven plots. On average, the simple exponential decay model produced through log-transformation and linear mixed model estimation overestimated the time to reach $0.03 \mathrm{bts} / \mathrm{tn}$ by nearly 1 week. This tends to be conservative from a snake control point of view in that only one of the seven plots required more weeks than predicted. Problems also arise for the log-transform/mixed linear model in the initial stages of trapping where the maximal capture rate that could be accommodated with the model was $0.208 \mathrm{bts} / \mathrm{tn}$, and three of the eight plots exceeded this value for the first week's capture rate $(0.222,0.224,0.242)$. The maximal capture rate that can be accommodated by the exponential decay with positive asymptote was $0.530 \mathrm{bts} / \mathrm{tn}$, which we never achieved for trapping a plot.

For the simple exponential decay with log-transform and mixed linear model estimation, and for exponential decay with asymptote and nonlinear mixed model estimation, we repeated the above procedures while excluding one of the eight plots at a time (Table 4). The same predicted fourth week capture rate of $0.02 \mathrm{bts} / \mathrm{tn}$ resulted in seven of eight cases for both models, with a capture rate of $0.03 \mathrm{bts} / \mathrm{tn}$ predicted when plot 8 was excluded. The predicted number of weeks to reach a capture rate of $0.03 \mathrm{bts} / \mathrm{tn}$ remained the same for six of eight cases for the simple exponential decay, while the prediction remained unchanged for all eight plots for the exponential decay plus asymptote.

\section{CONCLUSIONS}

The most useful general model for describing brown tree snake capture rates from discrete forested plots on Guam was an exponential decay with a positive, but low, asymptote. This model performed well predictively and the inclusion of an asymptote reflects the real-world situation where snake removals become balanced by repopulation pressures (probably re-invasion primarily). The model was produced using nonlinear mixed model procedures and allowing variability among plots to be introduced through both the scale and asymptote parameters. This requires sophisticated software and statistical background. On the other hand, a general simple exponential decay model could be produced by someone with elementary statistical training using a calculator that calculates natural logarithms and simple linear regressions. A linear regression model could be produced for each plot and the parameters averaged over all plots, and the average scale parameter back-transformed (backtransformation is unnecessary for the rate parameter) to produce a general exponential decay model. This model would yield similar or conservative longer-range predictions (which is more where our model practicality criteria lie). However, any call for predictions early in the curve, such as what the next week's capture rate would be given the first week's, could be poor from the simple model. Thus, we would discourage this approach, except as a stop-gap measure.

Our criteria for testing the general equation were based on management practicality, and the exponential decay model with asymptote should provide useful guidelines for brown tree snake 
Table 4. Cross-validation results from fitting general decay models for brown tree snake weekly capture rate from eight individual plots on Guam whereby each plot is excluded from the analyses in turn, and used to validate the modeling results. Observed data are given in Table 3

\begin{tabular}{|c|c|c|c|c|c|}
\hline \multirow[b]{3}{*}{$\begin{array}{l}\text { Excluded } \\
\text { plot }\end{array}$} & \multicolumn{5}{|c|}{ Linear mixed model } \\
\hline & \multicolumn{2}{|c|}{ Parameter estimates } & \multirow[t]{2}{*}{ Predicted } & & \\
\hline & Scale & Rate & & $\begin{array}{l}\text { Cap rate } \\
\text { at } 4 \text { wks }\end{array}$ & $\begin{array}{l}\text { No. wks to } \\
0.03 \text { bts/tn }\end{array}$ \\
\hline 1 & 0.200 & \multicolumn{2}{|r|}{0.589} & 0.02 & 3 \\
\hline 2 & 0.198 & \multicolumn{2}{|r|}{0.568} & 0.02 & 4 \\
\hline 3 & 0.189 & \multicolumn{2}{|r|}{0.571} & 0.02 & 4 \\
\hline 4 & 0.226 & \multicolumn{2}{|r|}{0.596} & 0.02 & 2 \\
\hline 5 & 0.249 & \multicolumn{2}{|r|}{0.628} & 0.02 & 1 \\
\hline 6 & 0.217 & \multicolumn{2}{|r|}{0.581} & 0.02 & 2 \\
\hline 7 & 0.212 & \multicolumn{2}{|r|}{0.606} & 0.02 & 3 \\
\hline \multirow[t]{3}{*}{8} & 0.182 & \multicolumn{2}{|r|}{0.481} & 0.03 & 3 \\
\hline & \multicolumn{5}{|c|}{ Nonlinear mixed model with asymptote } \\
\hline & \multicolumn{3}{|c|}{ Parameter estimates } & \multicolumn{2}{|c|}{ Predicted } \\
\hline $\begin{array}{l}\text { Excluded } \\
\text { plot }\end{array}$ & Scale & Rate & Asymptote & $\begin{array}{l}\text { Cap rate } \\
\text { at } 4 \text { wks }\end{array}$ & $\begin{array}{l}\text { No. wks to } \\
0.03 \mathrm{bts} / \mathrm{tn}\end{array}$ \\
\hline 1 & 0.518 & 1.332 & 0.020 & 0.02 & 2 \\
\hline 2 & 0.414 & 1.129 & 0.019 & 0.02 & 3 \\
\hline 3 & 0.619 & 1.519 & 0.021 & 0.02 & 2 \\
\hline 4 & 0.503 & 1.215 & 0.021 & 0.02 & 2 \\
\hline 5 & 0.570 & 1.267 & 0.020 & 0.02 & 1 \\
\hline 6 & 0.530 & 1.265 & 0.021 & 0.02 & 2 \\
\hline 7 & 0.476 & 1.198 & 0.018 & 0.02 & 2 \\
\hline 8 & 0.496 & 1.219 & 0.022 & 0.03 & 2 \\
\hline
\end{tabular}

control managers. Prediction of capture rates after four weeks of trapping allows a monthly consideration for evaluating and allocating resources. It is unlikely that sufficient numbers of traps and personnel will ever be available to simultaneously address all sites on Guam in need of brown tree snake removal. Prediction of the number of weeks needed to reach a capture rate of 3 brown tree snakes per 100 trap-nights is aimed at the point of a decay curve where the steep initial decline in captures trails off into an asymptote. It is during the asymptote phase of captures that managers may wish to consider moving the bulk of their trap resources to the next site to be trapped, perhaps leaving some traps behind for any remaining snakes, or snakes that might be invading (re-invasion into trapped plots has been shown to be relatively slow, so large numbers of traps are not required: Engeman and Linnell, 1998).

The abilities to have reasonable predictions of capture rates after a specified amount of time, and to predict the time to reach a target capture rate once trapping has begun, provide brown tree snake control managers with a tool for planning and implementing a trapping campaign. Predictive capabilities will be especially valuable when a fixed number of traps are to be applied to a series of 
plots in an optimal sequence for removing brown tree snakes from a larger area. A snake control manager will be able to predict when certain numbers of traps should become available for deployment in another plot. Because plot size determines the numbers of traps required, the manager will be able to optimally target future plots based on current capture rates. Being able to plan trap usage avoids the inefficiency of making decisions after capture rates have already diminished to the point where traps need to be moved, and then hoping that the number of freed traps lines up well with the sizes of plots to be trapped next.

\section{ACKNOWLEDGEMENTS}

G. Zerbe provided valuable input on modeling approaches. We thank J. Eisemann, G. Rodda and J. Shivik for their helpful reviews. The research was conducted under funding provided to the U.S. Department of Agriculture/Animal and Plant Health Inspection Service/Wildlife Services Operations/ Washington State Director's Office by the U.S. Department of Defense under DOD MIPR-064-95, 'Operational Control of Brown Tree Snakes in Guam', and with funds provided to the National Wildlife Research Center through the U.S. Department of Defense Legacy Project Number 1281, 'Development of Chemical Control Methods for Brown Tree Snake Management.'

\section{REFERENCES}

Begon M, Harper JL, Townsend CR. 1996. Ecology: Individuals, Populations and Communities. Blackwell Science Ltd: Oxford. Box GEP, Lucas HL. 1959. Design of experiments in non-linear situations. Biometrika 46: 77-90.

Eberhardt LL, Thomas JM. 1991. Designing environmental field studies. Ecological Monographs 61: 563-573.

Engeman RM, Linnell MA. 1998. Trapping strategies for deterring the spread of brown tree snakes (Boiga irregularis) from Guam. Pacific Conservation Biology 4: 348-353.

Engeman RM, Linnell MA. in press. The effect of trap spacing on the capture of brown tree snakes on Guam. Journal of Wildlife Research

Engeman RM, Linnell MA, Pochop PA, Gamboa J. 1998a. Substantial reductions of brown tree snake (Boiga irregularis) populations in blocks of land on Guam through operational trapping. International Biodeterioration and Biodegradation 42 : 167-171.

Engeman RM, Sayama S, Linnell MA. 1998b. Operational utility of perimeter trapping for removing brown tree snakes (Boiga irregularis) from a defined area. The Snake 28: 19-22.

Engeman RM, Vice DS, Nelson G, Muña E. 2000. Brown tree snakes effectively removed from a large plot of land on Guam by perimeter trapping. International Biodegradation and Biodeterioration 45: 139-142.

Fritts TH, McCoid MJ. 1991. Predation by the brown tree snake (Boiga irregularis) on poultry and other domesticated animals on Guam. The Snake 23: 75-80.

Fritts TH, McCoid MJ, Gomez DM. 1999. Dispersal of snakes to extralimital islands: incidents of the brown tree snake (Boiga irregularis) dispersing to islands in ships and aircraft. In Problem Snake Management: The Habu and Brown Tree snake. Rodda G, Sawai Y, Chiszar D, Tanaka H (eds). Cornell University Press: Ithaca, NY; 209-223.

Fritts TH, McCoid MJ, Haddock RL. 1990. Risks to infants on Guam from bites of the brown tree snake (Boiga irregularis). Amer. J. Trop. Med. Hyg. 42: 607-611.

Fritts TH, Scott NJ, Savidge JA. 1987. Activity of the arboreal brown tree snake (Boiga irregularis) on Guam as determined by electrical outages. The Snake 19: 51-58.

Graybill FA. 1976. Theory and Application of the Linear Model. Belmont, Calif: Duxbury.

Greene HW. 1989. Ecological, evolutionary, and conservation implications of feeding biology in Old World cat snakes, genus Boiga (Colubridae). Proc. Calif. Acad. Sci. 46: 193-207.

Grizzle JE, Allen DM. 1969. Analysis of growth and dose response curves. Biometrics 25: 357-381.

Laird NM, Ware JH. 1982. Random-effects models for longitudinal data. Biometrics 38: 963-974.

Linnell MA, Engeman RM, Pitzler ME, Watten MO, Whitehead GF, Miller RC. 1998. An evaluation of two designs of stamped metal trap flaps for use in the operational control of brown tree snakes (Boiga irregularis). The Snake 28: 14-18.

Linnell MA, Rodriguez DV, Mauldin RE, Engeman RM. 1997. Boiga irregularis: incubation and diet. Herpetological Review 28: 153 . 
Littell RC, Milliken GA, Stroup WW, Wolfinger RD. 1996. SAS System for Mixed Models. SAS Institute: Cary, NC, U.S.A.

McCoid MJ, Fritts TH, Campbell EW, III. 1994. A brown tree snake (Colubridae: Boiga irregularis) sighting in Texas. Texas Journal of Science 46: 365-368.

Rao CR. 1965. The theory of least squares when the parameters are stochastic and its application to the analysis of growth curves. Biometrika 52: 447-458.

Rawlings LR, Whittier J, Mason RT, Donnellan SC. 1998. Phylogenetic analysis of the brown tree snake, Boiga irregularis, particularly relating to a population on Guam. In Brown Tree snake Research Symposium, Campbell E, Rodda G (eds). Honolulu, HI; 31.

Rodda GH, Fritts TH. 1992. The impact of the introduction of the colubrid snake Boiga irregularis on Guam's lizards. J. Herpetol. 26: 166-174.

Rodda GH, Fritts TH, McCoid MJ, Campbell EW, III. 1999. An overview of the biology of the brown tree snake in small plots. In Problem Snake Management: The Habu and Brown Tree snake, Rodda G, Sawai Y, Chiszar D, Tanaka H (eds). Cornell University Press: Ithaca, NY; 44-80.

SAS Institute. 1999. SAS/STAT User's Guide, Version 8. SAS Institute: Carey, NC, U.S.A.

Savidge JA. 1987. Extinction of an island forest avifauna by an introduced snake. Ecology 68: 660-668.

Savidge JA. 1988. Food habits of Boiga irregularis, an introduced predator on Guam. J. Herpetol. 22: 275-282.

Shine R. 1991. Strangers in a strange land: ecology of Australian colubrid snakes. Copeia 1991: 120-131.

Shivik JA, Clark L. 1999. Ontogenetic shifts in carrion attractiveness to brown tree snakes (Boiga irregularis). Journal of Herpetology 33: 334-336.

Stowe CA, Jackson LJ, Carpenter SR. 1999. A mixed-order model to assess contaminant declines. Environmental Monitoring and Assessment 55: 435-444.

Wiles GJ. 1987. The status of fruit bats on Guam. Pac. Sci. 41: 148-157.

Wolfinger RD. 1999. Fitting nonlinear mixed models with the new NLMIXED procedure. In Proc 24th Annual SAS User's Group International Conference. SAS Institute: Cary, NC, U.S.A.; 1666-1675.

Zeger SL, Liang KY, Albert PS. 1988. Models for longitudinal data: a generalized estimating equation approach. Biometrics 44: $1049-1060$ 